\title{
RULES OF COMPOSITION: A MEREOLOGICAL EXAMINATION OF THE DAO-YOU RELATION
}

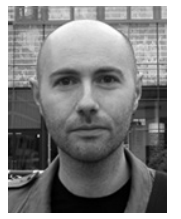

\section{Rafał Banka}

Centre for Comparative Studies of Civilisations, Faculty of Philosophy, Jagiellonian University

rafal.banka@uj.edu.pl

\subsection{Introduction}

From an ontological standpoint, it generally can be stated that what constitutes a signature feature of Daoism, as presented in the Daodejing 道德經, is the relation between dao 道 and you 有. Therefore, it is highly important how these fundamental elements of Daoist ontology are conceived; their conceptualization organizes the whole ontological model that can be reconstructed based on the Daodejing.

In this article, I would like to propose a plausible analysis of the relation that views dao and you in mereological terms, which can be successfully achieved by a monistically oriented mereology. This approach can lead to a coherent reconstruction of Daoist ontology in the Daodejing, and concurrently remain consistent with the wider non-dualistic worldview in classical Chinese philosophy. I intend to show this relation of opposition in terms of the ontic subregional relation of dao and you within a mereological paradigm. Following monism, I treat the two composites as qualitativelythat is, substantially_identical. ${ }^{1}$ In order to determine the differentiating aspect, I analyze dao and you in terms of their rules of composition-that is, determine how they can be mereologically described as objects. The rules of composition are combined with the modes of objects' persistence through time. In my mereological reconstruction, I will show that dao is an atemporal, unrestricted composition, whereas you is a temporal, restricted composition.

I believe that a major advantage of this approach lies in the fact that a large part of mereology focuses on an ontically one-dimensional (most frequently material) world and analyzes the way it is constructed. ${ }^{2}$ I think that this compatibility makes it plausible that a certain variant of mereology can be adjusted to the Daodejing. ${ }^{3}$

The importance of this particular approach can be additionally supported by the state of the art in metaphysics. Considering that mereology is regarded as one of the most essential subjects in contemporary metaphysics, ${ }^{4}$ examining its possible contribution to Chinese philosophy is of contemporary significance. Not only does it consist in examining a new interpretation of the dao-you status and relation but it also challenges the 
mereological conception with a substantially perplexing ontological model from a non-Western philosophical tradition.

I have divided this article into three parts, in which I (1) explain the general idea of my proposal and provide the mereological definitions and axioms that I will use in the reconstruction of dao and you, (2) interpret dao and you in monistic-materialistic terms, and (3) thus enable myself to proceed to their mereological reconstruction and conclusions.

\subsection{Mereological Objects}

A first attempt at accommodating Chinese ontology with mereological tools can be attributed to Chad Hansen's Language and Logic in Ancient China (1983). Despite the fact that Hansen's interpretation of Chinese ontology is not free from controversy, ${ }^{5}$ I think that his conception of mereological objects deserves being revisited here as it can lead to a coherent mereological reconstruction of dao and you.

Hansen starts from the observation that, according to classical Chinese semantics, what is denoted by language is the world of concrete, overlapping, and interpenetrating stuffs or substances, instead of abstract concepts. The consequence of refusing existence to abstract entities makes Hansen resort to a mereological description of Chinese metaphysics. Among other things, it entails supplanting set theory with a mereological conception, whereby sets are understood in terms of mereological objects (MO). An $\mathrm{MO}$ is understood as all the parts (in set theory all set members) that constitute discontinuous stuff. ${ }^{6}$ For instance, the denotation of the word "cat" is an MO that consists of all cats in the world. It can also denote part of the MO-that is, a number of cats fewer than in the whole MO. The identification of a set member in mereological terms is a concrete, spatiotemporal identification of part of an $\mathrm{MO}^{7}$ as distinct from other stuffs. For instance, identifying a cat would not consist in stating that the object is, for example, a non-vegetarian domestic mammal, but simply in applying the name "cat" to part of a concrete MO cat, or the whole cat-stuff/collection.

Despite the fact that supplanting abstract semantics with concrete differentiation can raise serious doubts not only in Chinese philosophical thinking, ${ }^{8}$ mentioning the ontological model above is important in my further discussion for the following reason: Hansen's MOs are "generic stuffs" of the same ontic status in the way that they are concrete and distinguishable objects. I think that dao and you can be referred to as two opposite MOs, which can be understood as a special case of mereological sums. In my opinion, they can be distinguished on account of the difference in their composition and persistence through time. Concurrently, bearing in mind that dao and you constitute a dynamic universe characterized by incessant transformation, the differentiation that would treat the two subregions of the Daoist ontic universe as static would violate one of the most essential assumptions underpinning 
Daoism, on both a cosmological and an ontological level. For this reason, in my discussion of the dao-you relation I also consider their interaction, which I describe as a form of causation. To render my account of causation consistent with mereological composition, I explain it in terms of the rules of both the composition of the two objects and their persistence through time.

\subsection{Rules of Composition and Persistence through Time as Ontological Differentials}

As mentioned above, I believe that the distinction between dao and you can be made by means of reconstructing the rules of composition for each of them. For the sake of further discussion, I introduce the basic definitions of part, overlap, sum, and rules of composition. I also introduce the notions of three- and four-dimensionalism, which I will need in order to reconstruct the causal relation of dao and you.

In mereology, proper parthood (being a part that concurrently is not the whole object it composes) is defined in the following way:

$x$ is a proper part of $y$ iff $x<y \& x \neq y .{ }^{9}$

I hereafter use the word "part" in the meaning of proper part.

Overlap is defined as follows:

$x$ and $y$ overlap $(x o y)$ iff for some object $z, z<x$ and $z<y$ (things overlap when they have a part in common $)^{10}$

Mereological sum (otherwise referred to as fusion) is defined in the following way:

$y$ is a sum of the $x s={ }_{d f}$ every one of $x s$ is a part of $y$ and every part of $y$ overlaps at least one of the $x s^{11}$

Rules of composition define what makes a mereological sum. They are responses to the so-called Special Composition Question: "What necessary and jointly sufficient conditions must any xs satisfy in order for it to be the case that there is an object composed of those $x s ?^{\prime \prime 12}$

There is a considerable variety of rules of composition that differently define sums. For instance, one can propose a rule consisting in adherence, according to which a sum is formed only if its parts are in physical continuity. It significantly differs from, for example, a systemic composition, where parts have to constitute a system. Thus, a clockwork would be a sum in both cases, whereas the Solar System only in the latter. ${ }^{13}$

Whereas rules of composition employ limitation to qualify entities for sums, and hence they are referred to as restricted compositions (RC), there is also a special type of composition that in the radical version grants the status of sum to any arrangement of any parts. This is unrestricted composition (UC), otherwise named mereological universalism. ${ }^{14}$ For instance, based on the 
example above, the clockwork and Mars constitute here a mereologically legitimate sum. I will discuss UC more closely in the section on mereological reconstruction.

As regards persistence through time, Ned Markosian distinguishes between three- and four-dimensionalism. According to four-dimensionalism (4D), "objects persist through time by having different temporal parts at the different moments at which they are present." This contrasts with threedimensionalism (3D), which is the thesis that "objects persist through time by being wholly present at each moment at which they are present."15 Thus, for instance, the 3D objecthood of a cup is dependent on whether it is chipped or not, whereas its 4D objecthood identifies it as the same cup before and after it is chipped.

I assume that dao and you are specifically conceived of as different mereological sums, and are irreducible to what we call "ordinary" things in everyday experience. First and foremost, the difference lies in the fact that things are examples of some mereological sums, as these may include entities whose "objecthood" is considerably counterintuitive. ${ }^{16}$ For instance, it is intuitive to admit that a car is an object composed of car parts, which is quite the opposite in the case of, say, a sum whose parts are: a car, a pen, and a tree.

Second, dao and you, because of their being "mass" or "collective" objects, depending on the interpretation, are concurrently generic, as opposed to what is generally conceived of as a thing, in the sense of the latter being singular in addition to concrete. As so conceived of as MOs, dao and you both exhaust the whole ontic universe. Considering this, distinguishing them from each other is not simply a differentiation between "commonplace" objects. Although the two are concrete entities, the distinction is of a generic nature. This particular variety of relation between mereological sums is different from, for example, a lack of spatial overlapping between other mereological sums.

Third, whereas mereology aims at determining a universal-composition rule that should preferably apply to all objects, Daoist ontology requires two rules of composition, each of which is applicable to the two separate ontic regions-dao and you. As will be shown, these rules are situated at two extremes-unrestricted and restricted. Moreover, as one deals with dynamic reality, the rules also have to address the issue of change, which is the mutual transformation of dao and you. I think that this aspect of the two mereological sums can be described in terms of how they persist through time. More specifically, the difference of dao and you as different MOs is conceptualized as 4D and 3D persistence types, respectively.

Summing up, the "generic" difference between dao and you hinges upon two different rules of composition, with associated time-persistence typesUC-4D and RC-3D, respectively - which, as I will show, are necessarily reconcilable within one ontic realm. The rules do not only allow one to state if something is a mereological sum-that is, a whole composed of parts. With equal importance, they also enable us to distinguish between 
what can be called dao-parthood and you-parthood, which exhausts the whole universe.

\subsection{Accordance with Mereological Axioms}

Before proceeding to the central question, it is necessary to examine if dao and you accord with the two basic axioms of mereology. Peter van Inwagen describes them in the following way:

(1) Parthood is transitive.

(2) For any $x$ s, those $x$ s have only one fusion. ${ }^{17}$

According to the first axiom, otherwise called parthood transitivity, if $x$ is part of $z$, and $y$ is part of $x$, then $y$ is part of $z$. The axiom can be fulfilled in two ways. The first one assumes a world composed of infinitely divisible elements, referred to by David Lewis as "atomless gunk."18 Accordingly, it implies that the world does not have the most basic elements, called singles, of which wholes and parts are made. This variant leads to the infinite regress in the sense that one can never attain mereological singles, which do not have parts. The second option assumes that there are mereological singles. In this case, the infinite regress is avoided.

Accordingly, assuming that the material world comes from dao, we are given two interpretations. As regards the first option, what originates from dao is the gunky material world. The gunky matter ( $w u$ 物) of whatever size or composition, is according to the Daodejing definable in terms of possessing forms (xing 形), which are necessary for the cognition of $w u$.

In the second option, dao "gives birth" (sheng 生) to singles, the most basic particles of the material world. This implies that there are traceable most basic material parts with forms xing. However, considering a wider horizon of Chinese metaphysical and cosmological thinking, especially considering the conception of $q i$ 氣, this alternative is highly implausible. ${ }^{19}$

Parthood transitivity is met in both cases; it either stops at singles, or plunges into the infinite "gunkiness." It is met within things (wu). Both variants from a certain perspective reveal a finite transitivity as they cannot go beyond the realm of things, which possess forms (youxing 有形). This guarantees parthood but also the existence of space-time regions that are essential in determining composition. Parthood cannot go beyond things, at least in the way it is formed for this ontic realm.

As for the second axiom, referred to as the uniqueness of sums, there is only one composition for given parts. This can at least be locally discussed in you when it is conceived of as an ontically independent region. However, whereas dao is considered, it depends on how broadly the composition can be understood. It should be noted that this axiom raises controversy in concrete material ontology. The axiom's holding in the Daodejing is even more complex on the grounds of a differentiated subregional universe. I will 
return to this issue in detail when reconstructing the two rules of composition for dao and you.

\subsection{Dao and You}

In this section, I will present my interpretation of dao and you. There are two main purposes underlying this task. First, it is essential to show why the difference between the two composites of reality is not dualistic. This in turn allows us to entertain a monistic-materialistic explanatory model, which I am about to reconstruct. Second, whereas you seems to be apt (indisputably at least compared with dao) to be accommodated by materialism, dao cannot be said to be exactly the same case. Hence, I intend to show that dao, despite being significantly different from the commonplace experience of objects, can be understood in materialistic terms, yet differently than you, and, as follows, one need not juxtapose it with you on ontic grounds.

The ontological content of the Daodejing largely hinges upon viewing dao in terms of opposition with you (understood as "ten thousand things" or wanwu, that is, the subregion of things). For this reason, I follow suit and concentrate on the relation rather than separate presentation of the two ontic subregions.

The opening chapter of the Daodejing already introduces dao, you, and their relation:

道, 可道, 非常道; 名, 可名, 非常名. 無名, 天地之始. 有名, 萬物之母. 故常無, 欲 以觀其妙，常有，欲以觀其徼. 有名，萬物之母. 此兩者同出而異名. ${ }^{20}$

The Tao (Way) that can be told of is not the eternal Tao;

The name that can be named is not the eternal name.

The Nameless is the origin of Heaven and Earth;

The Named is the mother of all things.

Therefore let there always be non-being so we may see their subtlety,

And let there always be being so we may see their outcome.

The two are the same,

But after they are produced, they have different names. ${ }^{21}$

Beginning with you, it constitutes the region that is nameable and describable. The fact that it "is the mother of all things" (wanwu zhi mu 萬 物之母) ${ }^{22}$ indicates that you is a world characterized by the plurality of distinguishable ${ }^{23}$ things, which I assume to be the commonplace world consisting of material objects. ${ }^{24}$

As regards dao, despite it being extralinguistic, it is essentially connected with you. It is described as the beginning of the universe, which suggests its 
antecedence, cosmological-temporal, or ontological-logical to the material world. Dao's precedence over you finds an even more explicit wording in Chapter 40:

\section{天下萬物生於有，有生於無 ${ }^{25}$}

All things in the world come from being.

And being comes from non-being. ${ }^{26}$

The discrete part of reality comes from you, the matter, which in turn comes from $w u$. However tempting it is to translate $w u$ as "non-being" or "nothingness," this is implausible not only because there would be origination from non-being to being, but also in the face of the statement from chapter 1 , according to which dao and you are the same, yet of different names. ${ }^{27}$ Thus, there is no difference on the ontic level. When it comes to language, the difference does not simply consist in the fact that the names denote different parts of reality (which in another sense is true) but that dao evades both adequate linguistic depiction and naming. This is confirmed in chapter 25:

吾不知其名, 強字之曰道, 強為之名曰大 ${ }^{28}$

I do not know its name; I call it Tao.

If forced to give it a name, I shall call it Great. ${ }^{29}$

This fragment explicitly shows that both allotting the character (zi 字) and referring to it by name (ming 名) result from an actual lack of choicethat is, the impossibility of determining the denotation in question. Thus, there is a twofold ontic realm, one part of which is denotable (you), and the other not (dao).

The fact that the linguistic reach is limited is attributed to forms, xing, which allow features to be identified (which are describable). However, one should not hastily conclude that dao is deprived of forms. The succinct statement 道, 冲而用之或不盈, 30 “Tao is empty (like a bowl), It may be used but its capacity is never exhausted"131 from chapter 4 finds development in chapter 41 as several evocative images. For instance, 大象無形, 32 "The great image has no form, ${ }^{\prime 33}$ does not suggest that the lack of form is tantamount to a complete absence of one. The formless great image is opposed to particular images, manifested in you and not on account of being all possible forms. The manifestation would entail actualizing part of them. Thus, dao and you are ontically the same, yet different in terms of form manifestation.

The Daodejing further determines the ontic features of dao. Dao's lack of forms makes it both indiscrete and complete (huncheng 混成). ${ }^{34}$ This is explainable in terms of wuxing, as their unmanifested character prevents dao from divisibility, so that completeness in oneness appears to be self-evident. The independent (duli 獨立) character of dao follows 
from the fact that it is dao from which everything originates. When it comes to dao's unchanging (bugai 不改), it should be mentioned that this refers to "observable" change in the material world. Quite the opposite, dao constitutes a dynamic reality that is omnipresent and active (zhouxing 周行).

Considering the preceding characteristic features of dao and you, one can assume the following ontological model: (1) dao is an undifferentiated material stuff (and thus indivisible oneness), for which reason (2) it cannot be linguistically encapsulated. (3) It is ontically independent and gives origin to the differentiated material world. ${ }^{35}$ (4) The non-differentiation results from having unmanifested forms. (5) Although significantly different from you, which is material reality discrete thanks to possessing manifested forms, dao and you are ontically the same. (6) Dao is antecedent to you in an ontological (and probably cosmological) sense. (7) It is unchanging in terms of altering forms, and in this very sense it can be understood as constant.

\subsection{Causality}

Up to this point, the preceding ontological model is considerably incomplete without a more thorough analysis of the dao and you dynamic relation. For the sake of the subject discussed in the article, I confine my discussion exclusively to the origination of the material part of reality differentiated from dao.

Quite intuitively, the relation should be viewed in causal terms. As can be seen, the causation employed in the ontological model of the Daodejing cannot be accommodated by the causation encapsulated as the isolated cause-effect scheme. This problem is addressed by Chung-ying Cheng in "Model of Causality in Chinese Philosophy: A Comparative Study" (1976), where he juxtaposes the Western and Chinese conceptions of causality.

Cheng describes the principles underlying the Western conception of causality. They involve:

(1) The principle of discreteness, according to which the world is composed of discrete entities.

(2) The principle of externality, according to which laws of causation externally manipulate objects. In other words, causality is not inherent in objects.

(3) The principle of external source of motion, according to which causation laws imply the ultimate cause (which was interpreted as, for example, the unmoved mover). ${ }^{36}$

Considering (1), causality understood in such a way cannot apply to dao. As regards you, it could conform with (1), but, considering the Chinese one-world view, (2) and (3) would not hold. This can be attributed to the discrepancy between the Chinese holistic worldview and what Cheng refers to as "atomistic-mechanistic" ${ }^{37}$ causation in the West. 
Cheng proposes a reconstruction of causality that underlies metaphysical-cosmological thinking in almost every school of Chinese thought. He summarizes it as three principles:

(1) The principle of holistic unity, according to which all things are generated from one source and thus, analogously with family members, are necessarily interrelated.

(2) The principle of internal life-movements, according to which things have an intrinsic "life-force" that is inherited from the source.

(3) The principle of organic balance, according to which processes in the world are characterized by a harmonizing pattern. ${ }^{38}$

Compared with the Western principles, (1) shows that Chinese causality is far more complex, as the causal relation cannot be easily isolated from the interconnected and interactive world. Attributing causality to a one-toone isolated relation does not hold in this case. As regards (2), there is no external "driving force" that puts things in motion. Instead, things have an intrinsic ability to move, which prevents causation from being viewed in terms of discrete causes and effects. Finally, from (3) one can learn that there is an order characterizing the whole reality, which means that causality is not confinable to local "causal circuits."

Considering the characteristic features above of Chinese causation, its Western counterpart is unable to map this aspect of Chinese ontology. Also, even if you, as an area of materialistically discrete objects, may seem to be describable in the language of causation, one has to bear in mind that you is not disentangled from dao. Remembering that it necessarily constitutes the organismic whole, causation ${ }^{39}$ cannot work locally in either dao or you. Hence, it is impossible to employ two different causalities here.

Dao meets (1) of the Chinese model in the sense that as undifferentiated matter it is the basis for everything that emerges from it. Concurrently, on its origination, you is necessarily connected with dao. As regards (2), by exhausting the ontic universe, dao and you do not leave space for extrinsic causation. As for (3), the question concerning the nature of dynamic harmonizing patterns constitutes a subject for a separate discussion. ${ }^{40}$ Therefore, I remain at the general level of parthood. I assume that parts, by virtue of composing objects, are causes for the whole as well as other parts. Thus conceived, causation can be compatible with all three Chinese causation principles. Accordingly, parts, whose feature is internal "lifemovements," are the causes of the existence of the sums in you. I will approach in more detail the issue of harmonizing pattern in my mereological reconstruction below in terms of 4D and 3D.

The analysis above of the ontic status of dao and you, as well as causation, creates a set of indispensable aspects of Daoist ontology that I believe can be accommodated in terms of composition and persistence through time. 


\subsection{Mereological Reconstruction: Rules of Composition}

In this section, I proceed to a mereological reconstruction of dao and you. I claim that the ontic universe of dao and you can be described by two pertaining rules of composition. This might appear counterintuitive because, as already shown, there is no ontic difference between the two regions and they are subject to one universal causation. However, there is no restriction imposed on the rules of composition in this respect-that is, they do not necessarily have to hold over the whole ontic region. In fact, rules of composition are quite often severely restricted, following the two mereological axioms at the same time. One can state that rules of composition permanently struggle with their extension limits, which in the case of Daoism might be an advantage.

Considering the ontic characteristics of dao and its "surface" difference with the discrete objects you, I think that they correspond to the opposition of $\mathrm{UC}$ / mereological universalism and $\mathrm{RC}$, respectively. Hence, I will try to determine what type of universalism can accommodate dao and, analogously, what type of restriction can successfully map you.

Mereological universalism challenges the workaday experience in which things are understood as discrete objects by holding that any collection of objects as parts constitutes another object. This variety of universalism complies with the parthood transitivity axiom, but does not exactly fulfill the other axiom, the uniqueness of sums. The previously mentioned formulation of van Inwagen's can be supplanted by that of Tarski due to the convenience of splitting it into two statements: "for any non-empty set of entities, there is at least... one entity that the members of that set compose," and "there is at most one" such entity. ${ }^{41}$ The conjunctive division is important because mereological universalism questions the latter part of the statement. Accordingly, any objects compose at least one whole, of which they are parts. This leads to the existence of an infinite number of sums.

The coexistence of an infinite number of objects ${ }^{42}$ contributes to the counterintuitive or even implausible character of mereological universalism. Lewis refers to mereological universalism as "unrestricted composition." The name reveals a very important aspect of mereological universalism, namely its contrast to mereological conceptions that develop rules of composition entailing characters and degrees of restricted compositions. As such, mereological universalism applies to mereological sums that are things as well as those which are not, on the grounds of the assumed rules of composition.

I think that the characteristics of mereological universalism have the potential to describe the indescribable, because it reveals an analogy with dao in that some sums are not covered by language (we have limited vocabulary or conventions for naming something a thing). From the standpoint of rules of composition they are inexistent, and thus a similar 
nothingness is imposed on them. Below, I systematically view mereological universalism against the characteristics of dao.

The undifferentiated character of dao consists in that, unlike discrete objects, it is not accessible through forms. Wanwu, on the grounds of being the reality of discrete objects, can be accommodated by a restricted composition. On the contrary, dao is describable in terms of mereological universalism in the sense that it exhausts all possible mereological sums, constituted by any collection of the entities that are their parts. Whether one assumes the gunk or singles as the foundation of the universe, the undifferentiated character of dao seems not to be affected by any of the choices. Hence what has no form (xing) can be attributed to the sums that do not qualify as things.

The relation to forms, translated into the distinctions between RC and $\cup C$, is also apt to explain the difference between the named and nameless. Our linguistic behavior (Hansen's conception of naming would be interesting here) is in a mutual relation with rules of composition-that is, the rules develop corresponding linguistic distinctions, and, vice versa, the linguistic distinguishing practice perpetuates the "legitimacy" of the rules. In light of this linguistic engagement in ordering reality, there emerges a "natural selection" of compositions that label things, and others which form a kind of "materialistic noise" or "stuff."

The same ontic status of dao and you is nearly self-evident. The monistic model in mereological universalism is retained and the differentiation between the two ontic regions (of the same ontic universe) is engineered by means of the valid composition (sub)rules (in the sense that we have the universal level of $\mathrm{UC}$, from whose perspective the RC for wanwu is a local pattern, but not an ontic property).

The ontic antecedence can be explained in the following way. Given that things constitute just a portion of all possible sums, one can say that their existence cannot exist apart from all existing sums. This antecedence is also tantamount to the independence of UC in that the relation is not reciprocal and no other conditioning is given.

Dao, by virtue of being undifferentiated, constitutes a complete oneness. Analogously, in mereological universalism all possible sums, which are concurrently parts of one mereological sum, concurrently fulfill the requirement of completeness. Considering that the universe is materialistic and thus composed exclusively of sums and parts (if we opt for mereological singles), the region of $U C$ is omnipresent by exhausting the whole ontic domain.

\subsection{Mereological Reconstruction: Causality}

Considering that the Daoist universe is dynamic and governed by a specifically conceived causality, the relation between $U C$ and RC subregions should be addressed. I believe that this issue can be explained in terms of 
how objects differ in the duration of their existence, in terms of the relation between 4D and 3D.

Ned Markosian claims that "UC entails 4D." 43 The parts that compose a given object existed before and continue to exist. Thus, from the combined UC-4D perspective, ${ }^{44}$ one can state that objects persist through time. What follows is that a "mereologically constant," atemporal object (4D) temporally overlaps with a mereologically "variable object (3D).." 45

Accordingly, the causal relation between dao and you can be viewed as a dynamic (because it also involves 3D) overlapping of dao, which persists through time and can change; however, thanks to UC the object is constant, with you understood as temporal objects. Therefore, dao can be described as UC-4D, whereas you as RC-3D. In what follows, I examine the three features of Chinese causation against this model.

As regards holistic unity, the two subregions are not disjunctive. The "layer" of UC-4D underpins RC-3D. Every temporal object is generated from UC-4D. The origination is subjected to natural processes, which involve UC-4D. When a temporal object comes into being, the constant object is unaffected in its "architecture" or quantity, which is guaranteed by UC.

During the existence of a temporal object, the two layers are constantly interconnected, because (a) they share parts, and (b) any change in UC-4D (which does not cause any ontological "dent" in it) influences the object in RC-3D. The ceasing of a temporal object does not affect the existence of UC-4D, and it could be conceived as the reversal to dao. As mentioned before, parts are causes, and thus the parts of UC-4D that overlap with RC-3D are concurrently its causes.

As far as intrinsic force is concerned, it is inherited as a common quality of overlapping objects in UC-4D and RC-3D. One can say that the intrinsic processes differ in their impact with regard to a given subregion-namely, they influence the temporal existence of an RC-3D object, in contrast with $U C-4 D$. As parts are causes of the objects they form in RC-3D, the intrinsic character of causality is met.

Finally, with regard to an overall harmonizing pattern, confining the explanation to RC-3D would result in the false statement that causality operates only within the realm of things-that is, the subset of all objects, which would contradict Chinese cosmology. Causality is to be viewed as operating in the totality rather than part of the universe. Therefore, the harmonious pattern can be viewed as the exchange of "objecthood" between the RC-3D and UC-4D subregions. The mereological overlap can also lead to whatever originates in RC-3D being necessarily a subset of all possible sums from UC-4D, and in this sense the overlap is an accordance. This in turn can be understood as a harmonizing patterning as it is implausible that there is an RC-3D that was not caused by UC-4D. 


\subsection{Conclusions}

The rendering of Daoist ontology in mereological terms does not simply prove that the dao-you relation can be accommodated with another possible conceptual scheme. First, it shows that the mereological approach allows one to further explore the relation between dao and you. In my opinion, one can entertain the hypothesis that the difference between UC and RC can be attributed to location, which can be assumed as identity for temporal - that is, RC-3D-objects. This in turn could lead one to examine, for instance, whether form (xing) can be conveyed in such terms.

Second, the RC-UC relation raises the question whether we can describe it in terms of inclusion. In such a case, one has to consider two options. Accordingly, if Daoist ontology is encapsulated within the RC perspective, dao would not fall into any RC category, which would result in a split between the reality of things and stuff (or stuffs). Dao would be viewed in terms of generic stuffs, whereas you would refer to generic collections.

The other option involves inclusion within UC. In such a case, the composition is "at large" - that is, everyday life things would just constitute a subregion of a more complex universe of mereological sums. The fact that it includes, inter alia, things can be attributed to non-ontological reasons, such as Hansen's "behavioral nominalism" or other conventions originating from human practice. Consequently, the RC objects appear to be reducible to language-relative constructs, contrary to the UC reality.

Third, the mereological approach also addresses an important issue concerning how precisely to reconstruct the two interconnected elements - parthood and causality. I believe that the former needs reconstruction as an atomless gunk. As regards the latter, I assume that one should depart from the statement that parts are causes of the sums they constitute to further determine the holistic, parthood-inherent and dynamic aspects of causality.

\section{Notes}

I would like to thank the two anonymous reviewers for their careful reading, insightful comments, and suggestions concerning the manuscript of this article.

1 - I.e., composed of the same ontic material.

2 - Of course, it does not imply that mereology is exclusively concerned with material objects. For instance, Peter Simons discusses, among other things, the mode of mereological occupation for universals. See Peter Simons, "Where It's At: Modes of Occupation and Kinds of Occupant," in Mereology and Location, ed. Shieva Kleinschmidt (New York: Oxford University Press, 2014), pp. 59-68. 
3 - In fact, at the same time it indirectly applies to the general one-world view, which pervades almost the whole of Chinese philosophy.

4 - This fact can be testified to by, for instance, including mereology among the most important subjects in Contemporary Debates in Metaphysics, ed. Theodore Sider, John Hawthorne, and Dean W. Zimmerman (2008). Also, there are two books dedicated to mereology, Mereology and Location, ed. Shieva Kleinschmidt, and Composition as Identity, ed. A. J. Cotnoir and Donald L. M. Baxter, published in 2014 by Oxford University Press.

5 - For instance, Mou Bo criticizes Hansen's mass-noun interpretation in favor of the collective-noun hypothesis, which is to underpin the Chinese mereological ontology. See Bo Mou, "The Structure of the Chinese Language and Ontological Insights: A Collective-Noun Hypothesis," Philosophy East and West 49, no. 1 (1999): 45-62.

6 - Hansen, Language and Logic in Ancient China (Ann Arbor: University of Michigan Press, 1983), p. 31.

7 - Ibid., p. 31.

8 - As Mou remarks, epistemologically speaking, abstraction cannot be omitted when conceptualizing classes or kinds of things. Any generalization should be regarded as abstraction (Mou, "The Structure of the Chinese Language," p. 53).

9 - The symbol "<" stands for "is part of." See James van Cleve, "The Moon and Sixpence: A Defense of Mereological Universalism," in Contemporary Debates in Metaphysics, ed. Theodore Sider, John Hawthorne, and Dean W. Zimmerman (Malden: Blackwell Publishing, 2008), p. 322.

10 - Van Cleve, "The Moon and Sixpence," p. 322.

11 - Ned Markosian, "Restricted Composition," in Sider, Hawthorne, and Zimmerman, Contemporary Debates in Metaphysics, p. 342.

12 - Ibid.

13 - Obviously, rules formed in such a rough way are very imprecise. For instance, in the case of the "systemic" rule, there appears a problem consisting in the sharp definition of what a system is and/or whether all systems can be labeled mereological sums.

14 - The term "mereological universalism" is used by van Inwagen, whereas David Lewis refers to it as "unrestricted composition." See van Cleve, "The Moon and Sixpence," p. 321.

15 - Markosian, "Restricted Composition," p. 345. 
16 - Hereafter, I use "thing" for what is commonly regarded as things, i.e., physical, discrete objects, whereas my usage of "object" refers to any mereological sums, including things.

17 - Peter van Inwagen, "Composition as Identity," Philosophical Perspectives 8 (1994): 207.

18 - See van Cleve, "The Moon and Sixpence," p. 323.

19 - Daoism, and Chinese metaphysics in general, is far more compatible with the view that the world is composed of gunk rather than ultimate parts. Examining how precisely the atomless gunk should be understood in Daoism is a subject for a separate discussion. In this article, I remain at a general level of parthood and refrain from proposing a plausible interpretation of gunkiness.

20 - Laozi, Laozi, annot. and trans. Shangkuan Rao (Beijing: Zhonghua Shuju, 2007), p. 2.

21 - Laozi, "The Laotzu (Tao-Te Ching)," in A Source Book in Chinese Philosophy, trans. and comp. Wing-tsit Chan (Princeton: Princeton University Press, 1970), p. 139.

22 - Ibid.

23 - Rao, Laozi, p. 2. One can infer it from wanwu 萬物, literally standing for "ten thousand things," which suggests countability.

24 - I do not discuss what material entities are as this is not immediately related to the subject of my article.

25 - Rao, Laozi, p. 100.

26 - Chan, "The Laotzu," p. 160.

27 - Ibid., p. 139.

28 - Rao, Laozi, p. 63.

29 - Chan, "The Laotzu," p. 152.

30 - Rao, Laozi, p. 11.

31 - Chan, "The Laotzu," p. 141.

32 - Rao, Laozi, p. 102.

33 - My translation.

34 - Chap. 25.

35 - It is well epitomized in chapter 51: 道生之, 德畜之, 物形之 (Rao, Laozi, p. 123); "Dao gives birth to them [everything], Virtue fosters them, Matter gives them physical form" (Chan, "The Laotzu," p. 163). It is worth noticing that Chan translates $w u$ 物 as "matter." 
36 - Chung-ying Cheng, "Model of Causality in Chinese Philosophy: A Comparative Study," Philosophy East and West 26, no. 1 (1976): 6.

37 - Ibid., p. 7.

38 - Ibid., p. 12.

39 - Excluding rule-of-thumb causal solutions.

40 - Among other things, it would require determining the nature of the non-particle of parts, which alone requires a separate discussion.

41 - After van Cleve, "The Moon and Sixpence," pp. 322-323.

42 - Assuming the gunky character of reality, every single object would be made of parts.

43 - Markosian, "Restricted Composition," p. 345.

44 - In addition to defining the types of persistence through time, Markosian also claims that UC entails 4D. See Markosian, "Restricted Composition," p. 345.

45 - Terminology used by Markosian, "Restricted Composition," p. 345.

References

Cheng, Chung-ying. "Model of Causality in Chinese Philosophy: A Comparative Study." Philosophy East and West 26, no. 1 (1976): 3-20.

Cotnoir, A. J., and Donald L. Baxter, eds. Composition as Identity. New York: Oxford University Press, 2014.

Hansen, Chad. Language and Logic in Ancient China. Ann Arbor: University of Michigan Press, 1983.

Kleinschmidt, Shieva, ed. Mereology and Location. New York: Oxford University Press, 2014.

Laozi. "The Laotzu (Tao-Te Ching)." In A Source Book in Chinese Philosophy, edited and translated by Wing-tsit Chan, pp. 139-176. Princeton: Princeton University Press, 1970.

- Laozi. Annotated and translated by Shangkuan Rao. Beijing: Zhonghua Shuju, 2007.

Markosian, Ned. "Restricted Composition." In Contemporary Debates in Metaphysics, edited by Theodore Sider, John Hawthorne, and Dean W. Zimmerman, pp. 341-363. Malden: Blackwell Publishing, 2008.

Mou, Bo. "The Structure of the Chinese Language and Ontological Insights: A Collective-Noun Hypothesis." Philosophy East and West 49, no. 1 (1999): 45-62. 
Sider, Theodore, John Hawthorne, and Dean W. Zimmerman, eds. Contemporary Debates in Metaphysics. Malden: Blackwell Publishing, 2008.

Simons, Peter. "Where It's At: Modes of Occupation and Kinds of Occupant." In Mereology and Location, edited by Shieva Kleinschmidt, pp. 59-68. New York: Oxford University Press, 2014.

van Cleve, James. "The Moon and Sixpence: A Defense of Mereological Universalism." In Contemporary Debates in Metaphysics, edited by Theodore Sider, John Hawthorne, and Dean W. Zimmerman, pp. 321-340. Malden: Blackwell Publishing, 2008.

van Inwagen, Peter. "Composition as Identity." Philosophical Perspectives 8 (1994): 207-220. 